\title{
The conservation imperative and setting plant taxonomic research priorities in South Africa
}

\author{
Janine E. Victor • Gideon F. Smith
}

\begin{abstract}
For more than a decade it has been internationally recognised that efforts should be made to remedy the concern that taxonomy is an endangered discipline in the grips of rapid decline. In acknowledgement of the perceived continuing marginalisation of taxonomy, the Darwin Declaration recognised the need to enhance the taxonomic capacity of members who are party to the CBD, and beyond. South Africa is one of the most biodiversity rich countries globally, and the unique and rich flora of the country brings with it a significant conservation imperative. Although the country, and southern African sub-region for that matter, has a strong history of taxonomic endeavour, stretching back for over a century, it also suffers from a lack of human and other resources to adequately address its taxonomic needs. This inevitably calls for a process of priority-setting to ensure the wise use of available funding. As one example, it is shown that 1,009 indigenous South African plant taxa are regarded as Data Deficient for taxonomic reasons, following the completion of a recent comprehensive Red Listing exercise. Although not the only criterion to be considered when prioritising taxonomic research, efforts focused on these groups represent a significant opportunity for taxonomists to align their work with national priorities.
\end{abstract}

\section{J. E. Victor (corresponding author)}

National Herbarium, South African National Biodiversity Institute, Private Bag X101,

Pretoria 0001, South Africa

e-mail: J.Victor@sanbi.org.za

\section{G. F. Smith}

Biosystematics Research \& Biodiversity Collections, South African National Biodiversity Institute,

Private Bag X101, Pretoria 0001, South Africa

G. F. Smith

H.G.W.J. Schweickerdt Herbarium, Department of Plant Science, University of Pretoria, Pretoria 0002, South Africa

\section{G. F. Smith}

Departamento de Cie^ncias da Vida, Centre for Functional Ecology, Universidade de Coimbra, 3001-455 Coimbra, Portugal 
Abbreviations

CBD Convention on Biological Diversity

SBSTTA Subsidiary Body on Scientific, Technical and Technological Advice

GTI Global Taxonomy Initiative

SANBI South African National Biodiversity Institute

PRE National Herbarium, Pretoria

PRECIS National Herbarium, Pretoria (PRE) Computerised Information System

DD Data Deficient

EIA Environmental impact assessment

IUCN International Union for Conservation of Nature

The importance of taxonomy, the science of detecting, describing, naming and classifying biological organisms, as a fundamental discipline requisite for all other fields of biological science is undisputed (Lowry and Smith 2003; Wilson 2003, 2004; Smith et al. 2008). However, despite the wide recognition and support expressed for taxonomy, a 'taxonomic impediment' referring to diminishing capacity to perform basic taxonomic research, has been recognised since the second meeting of the SBSTTA of the CBD held in 1997. Significantly, the Darwin Declaration (Environment Australia 1998) called for investment by governments in biological collections in terms of development of capacity and infrastructure. The importance of taxonomy in conservation and management of the world's biodiversity therefore has the support of the Conference of Parties to the CBD, which resulted in the establishment of the GTI at the fourth meeting in 1998. Despite this admirable development, there are growing concerns that the discipline is struggling (Lowry and Smith 2003), weakened by the increasing difficulty in procuring funding for research and for maintaining collections (Wilson 2004). This is in part due to the nature of taxonomy as an established and fundamentally descriptive science. Adding to this, products of taxonomic work, such as scientific publications, are widely used without being cited, resulting in taxonomic publications being measured as of low impact (Agnarsson and Kuntner 2007). More prestigious and fashionable fields of study are preferentially given funding, in spite of many essays and papers justifying why there is a critical need to prioritise constant updating of taxonomic knowledge (see for example Khuroo et al. 2007, Cresswell and Bridgewater 2000).

At several institutions with a proud history of taxonomic research there has been a steady decline in the number of employees over the past few years, as aged taxonomists retire or younger employees depart for improved prospects and their posts are not filled. This trend has been reported in the literature for many countries that are signatories to the CBD (Cogalniceanu et al. 2007), yet it is in conflict with the operational objective of the programme of work of the GTI, i.e. developing or strengthening human capacity to generate information (operational objectives 2 and 3, see CBD website at http://www. biodiv.org/convention/result.aspxid=7182).

With the recent completion of a Red Listing initiative that covered the entire South African flora, it was shown that for over 1,000 plant taxa insufficient data are available to accurately assess their conservation status. We confirm the importance of taxonomy, and argue that increased relevance for the discipline can be derived from a focus that, among 
other things, comprehensively embraces taxa that require taxonomic resolution to improve knowledge of their conservation.

Callmander et al. (2005) appeal for plant taxonomists to mobilise to identify threatened species using available distribution data and include preliminary Red List assessments in taxonomic works. As a result of extensive field experience, taxonomists almost invariably have the knowledge to do this. Justifiably therefore staff of the Threatened Species Programme of SANBI placed heavy reliance on taxonomic expertise in conducting Red List assessments (Raimondo et al. 2009; Victor 2002). Without primary data, no comparison between the current and historical status of species is possible, and the task of assessing threat status, and subsequently, informing conservation management, would be insurmountable. This is the case in Brazil (Brito 2004), and in India and Sri Lanka, where taxonomic research has also declined (Pethiyagoda et al. 2007).

The Red List status of many taxa indigenous to South Africa has not been adequately assessed because of uncertainties in their taxonomic status. These were classified as DD, since, according to IUCN (2001), a taxon qualifies for this category when "there is inadequate information to make a direct, or indirect, assessment of its risk of extinction based on its distribution and/or population status'. However, there was a need to distinguish taxa that were DD for taxonomic reasons from those that were DD for other reasons. The use of the letter " $T$ "' was therefore adopted to flag those species, while those entities that were DD due to insufficient information regarding threats or population statistics were flagged with the letter " D', (Victor 2006).

There are currently 1,009 plants, or about 9\% of the South African flora, that are recorded as DDT on the Red List (Raimondo et al. 2009). Furthermore, taxonomic problems have been identified in some threatened and DDD plant species. This is partly a result of the nature of the process for assessing the threat status. Taxonomically problematic species are often known from only one or very few localities, and such apparently rare species are selected via the assessment process as being of conservation concern. It can be difficult to distinguish between truly rare and threatened species from those that simply appear to be very rare or threatened due to lack of taxonomic and other information. When taxonomically problematic species are listed as threatened or DD, conservation authorities have inadequate information to ensure the conservation and future survival of the species, and may neglect them in favour of better known species to justify the financial outlays. Conversely, conservation organisations have too little financial resources to spend on species that are taxonomically problematic when resources could be allocated to higher priority species. In addition to this, taxonomically problematic species that are threatened or DD still need to be taken cognizance of during EIA processes, often having significant fiscal implications for both conservation departments and developers, and hampering or delaying EIAs. If the taxonomic status is in doubt, this can lead to unnecessary wastage of financial resources. One of many such examples in South Africa is a rather obscure milkweed that had sunken into obscurity for 109 years. It was rediscovered in an area targeted for housing development. The plant in question, now known as Stenostelma umbulleliferum, resulted in a moratorium being put on development whilst taxonomists and conservationists collaborated to clarify both the taxonomic status and conservation status of the species (Bester and Victor 2005).

Taxonomic research targeted towards taxa with taxonomic problems, would have significant impacts on conservation of South Africa's biodiversity, particularly in regions of high economic development. The results of such studies are of great significance to the conservation community, in that their financial resources can be more effectively allocated to species of conservation priority. The outcomes of taxonomic research targeted to DD 

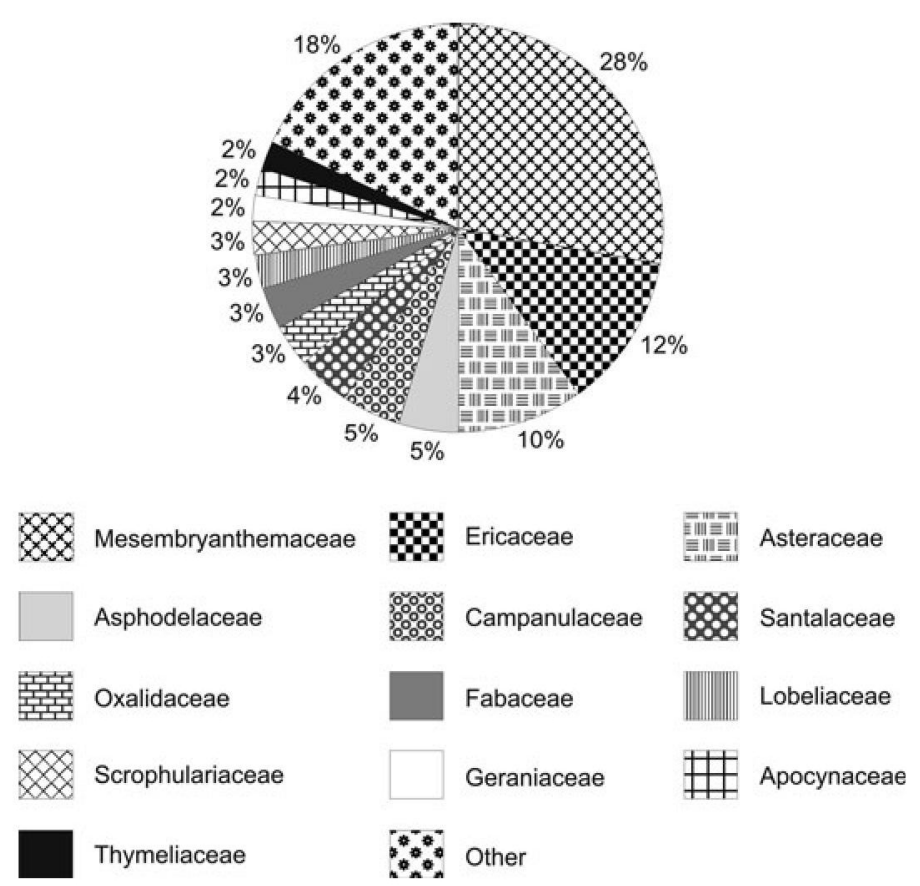

Fig. 1 Proportion of total of number of DDT species per family

and threatened species furthermore have significance and importance to developers and the South African economy, in improving the Red List and clarifying issues that could otherwise hinder both conservation and development, thus informing the science-policy interface.

One way to prioritise which plant families should receive focused taxonomic attention is therefore to analyse the proportion of species listed as DDT in each indigenous South African family. For the purposes of these analyses we have expressed the results as a percentage of the total number of DDT species. This provides information on which families have the most DDT species and are therefore most in need of taxonomic attention.

An analysis of DDT species on the current Red List (Fig. 1) shows that of the 254 plant families indigenous to South Africa, 13 have more than 20 members classified as DDT. Thus, these families are regarded as being priorities for focussed taxonomic attention. The family that contains the highest number of DDT species, and therefore is most in need of taxonomic attention, is the Mesembryanthemaceae, a family of succulent plants. A further 46 families contain fewer than 20 members classified as DDT, and 221 families out of 254 have no species classified as DDT.

One way to ensure that accurate and complete taxonomic information is available for end users in the face of diminishing resources is to concentrate efforts on two main foci of research: targeting specific taxonomic problems that have implications for other fields e.g. conservation; and compilation of accurate inventories for undercollected areas. Specifically there is an urgent need to focus taxonomic research on the families highlighted in the current paper. Taxonomists are required to keep abreast with existing thrusts (such as red listing) and new technologies and skills that can enhance understanding of species and their interrelationships. 
The taxonomic community has to maximise on this international recognition of the crucial importance of taxonomy if, among other things, conservation and related research is to succeed. In this regard taxonomists need to document and synthesize all knowledge and make it easily available to end users. Integrating taxonomic products with other fields of research will improve taxonomy-based products as well as improve potential funding opportunities (Agnarsson and Kuntner 2007). Ultimately, a sound taxonomic framework encompassing an understanding of phylogenetic relationships will "facilitate scientifically informed policies in conservation efforts and bioresource management" (Wheeler 1995). If South Africa is serious about preserving biodiversity and maximising on benefits that can be derived from it, the country cannot afford to neglect its taxonomists.

\section{References}

Agnarsson I, Kuntner M (2007) Taxonomy in a changing world: seeking solutions for a science in crisis. Syst Biol 56(3):531-539

Bester SP, Victor JE (2005) Schizoglossum umbelluliferum: an unusual milkweed re-collected in Pretoria after 109 years. Veld Flora Dec:166

Brito D (2004) Lack of adequate taxonomic knowledge may hinder endemic mammal conservation in the Brazilian Atlantic Forest. Biodivers Conserv 13:2135-2144

Callmander MW, Shatz GE, Lowry PP (2005) IUCN Red List assessment and the Global Strategy for Plant Conservation: taxonomists must act now. Taxon 54:1047-1050

Cogalniceanu D, Rusti D, Manoleli D (2007) Romanian taxonomy in crisis — present status and future development. Travaus du Museum National d'Histoire Naturelle 50:517-526

Cresswell ID, Bridgewater P (2000) The Global Taxonomy Initiative — quo vadis? Biol Int 38:12-16

IUCN (2001) IUCN Red List Categories and Criteria: version 3.1. IUCN Species Survival Commission.

IUCN, Gland

Khuroo AA, Dar GH, Khan ZS et al (2007) Exploring an inherent interface between taxonomy and biodiversity: current problems and future challenges. J Nat Conserv 15:256-261

Lowry PP, Smith PP (2003) Closing the gulf between botanists and conservationists. Conserv Biol 17(4):1175-1176

Pethiyagoda R, Gunatilleke N, De Silva M, Kotagama S, Gunatilleke S, de Silva P,Meegaskumbura M, Fernando P, Ratnayeke S, Jayewardene J, Raheem D, Benjamin S, Ilangakoon A (2007) Science and biodiversity: the predicament of Sri Lanka. Curr Sci 92:426-427

Raimondo D, von Staden L, Foden W et al (eds) (2009) Red List of South African plants. Strelitzia 25. South African National Biodiversity Institute, Pretoria

Smith GF, Buys M, Walters M et al (2008) Taxonomic research in South Africa: the state of the discipline. S Afr J Sci 104:254-256

Victor JE (2002) South Africa. In: Golding JS (ed) Southern African Plant Red Data Lists. Southern African Botanical Diversity Network Report 14:8-11

Victor JE (2006) Data Deficient flags for use in the Red List of South African plants. Bothalia 36(1):85-86 Wheeler QD (1995) Systematics, the scientific basis for inventories of biodiversity. Biodivers Conserv $4: 476-489$

Wilson EO (2003) The encyclopedia of life. Trends Ecol Evol 18(2):77-80

Wilson EO (2004) Taxonomy as a fundamental discipline. Philos Trans R Soc Lond B 359:739 